\title{
Magnetic Properties of Fe-Based Ribbons and Toroidal Cores Prepared by Continuous Joule Heating Under Tensile Stress
}

\author{
T. Yanai ${ }^{1}$, A. Shimada ${ }^{1}$, K. Takahashi ${ }^{1}$, M. Nakano ${ }^{1}$, Y. Yoshizawa ${ }^{2}$, and H. Fukunaga ${ }^{1}$ \\ ${ }^{1}$ Department of Electrical Engineering and Electronics, Nagasaki University, Nagasaki, 852-8521 Japan \\ ${ }^{2}$ Advanced Electronics Research Laboratory, Hitachi Metals Ltd., Kumagaya, 360-0843 Japan
}

\begin{abstract}
Nanocrystallized $\mathrm{Fe}_{73.5} \mathrm{Cu}_{1} \mathrm{Nb}_{3} \mathrm{Si}_{15.5} \mathrm{~B}_{7}$ ribbons with controlled permeability were prepared by using continuous stress-annealing by Joule heating (CSA-JH) method. An optimization of the annealing conditions revealed that a completely developed anisotropy perpendicular to the ribbon axis can be obtained stably in the moving velocity range from 1 to $200 \mathrm{~cm} / \mathrm{min}$ at the current density of 37.5 $\mathrm{A} / \mathrm{mm}^{2}$. In particular, the highest velocity of $200 \mathrm{~cm} / \mathrm{min}$ achieved the significant reduction in effective annealing time. The core made from the above-mentioned ribbon had good ac-magnetic properties such as constant permeability up to 2 MHz and low magnetic loss compared with those for different types of cores with controlled permeability.

Consequently, it was clarified that the CSA-JH method is one of effective techniques for production of high performance toroidal cores with controlled permeability.
\end{abstract}

Index Terms-Continuous stress-annealing, controlled permeability, Joule heating, magnetic toroidal core, nano-crystalline, stressinduced anisotropy.

\section{INTRODUCTION}

$\mathbf{I}$ $\mathrm{N}$ order to advance the high-density packaging and energy saving of electric devices, size reduction and improvement in efficiency of magnetic cores are strongly required. We, therefore, proposed several kinds of Fe-based toroidal cores with controlled permeability and low loss, and showed that they could be applicable to choke coils [1]-[4].

A choke coil operates under dc-bias field and we need to control its permeability at several hundreds, because it operates under dc-bias field. For preparation of a high performance magnetic core with controlled permeability, we used a uniaxial magnetic anisotropy developed perpendicularly to the ribbon axis by stress-annealing, because the perpendicular anisotropy leads the magnetization rotation mode and reduces magnetic loss. From the viewpoint of improving the controllability of the permeability, we have reported several methods of stress-annealing such as the continuous stress-annealing with a furnace (CSA-F) [5]-[7] and the Joule-heating under tensile stress (JH) [8]-[11]. Although both the methods are hopeful candidates for obtaining a ribbon with controlled permeability, the CSA-F method needs a furnace and the $\mathrm{JH}$ method had difficulty in obtaining a long ribbon efficiently.

We, therefore, developed a fabrication method which combines the advantages in each method. This contribution reports the developed method, which was called the continuous stressannealing by Joule-heating (CSA-JH) method, with the potential for high productivity.

Digital Object Identifier 10.1109/TMAG.2006.880078
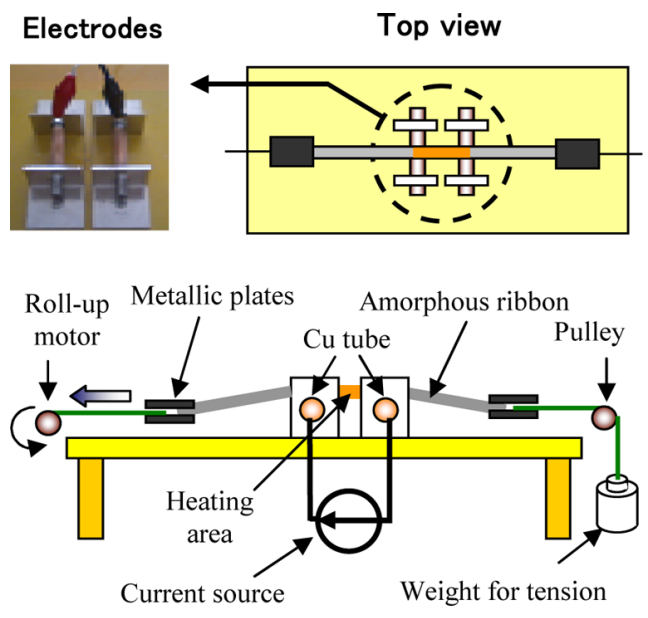

Side view

Fig. 1. Schematic representation of apparatus for continuous stress-annealing by Joule heating. (Color version available online at http://ieeexplore.ieee.org.)

\section{EXPERIMENTAL PROCEDURE}

\section{A. Annealing for Development of Anisotropy}

Amorphous ribbons (Hitachi Metals Ltd.), 200 or $500 \mathrm{~mm}$ in length, $2 \mathrm{~mm}$ in width, and $20 \mu \mathrm{m}$ in thickness, were annealed under tensile stress, $\sigma$, from 50 to $175 \mathrm{MPa}$ by the CSA-JH method in air. The apparatus used for the annealing is shown in Fig. 1. Rotatable $\mathrm{Cu}$ tubes connected with a dc-current source were used as electrodes, and the ribbon was kept contact with the electrodes under CSA-JH. The supplied current density, $j$, and the moving velocity, $v_{m}$, of the ribbons were varied from 32.5 to $42.5 \mathrm{~A} / \mathrm{mm}^{2}$ and from 1 to $200 \mathrm{~cm} / \mathrm{min}$, respectively. Magnetic anisotropy was developed perpendicularly to the ribbon axis through the stress-annealing, which changes the magnetization mode to the rotation mode from the domain wall displacement one [12]-[15]. Details of the origin of anisotropy de- 


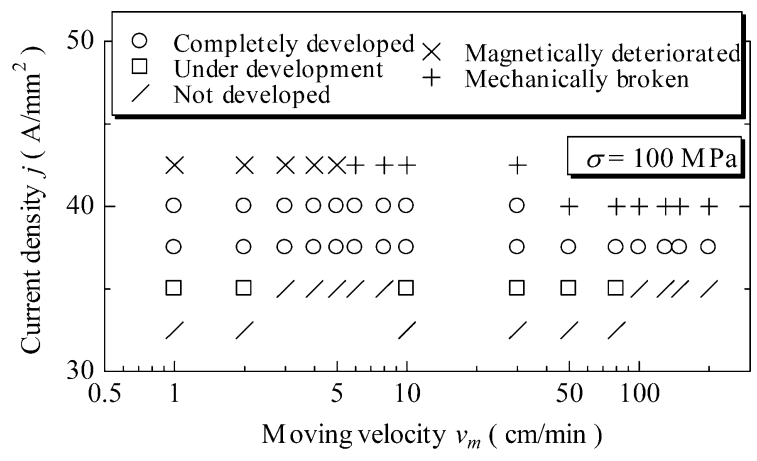

Fig. 2. Relationship among development state of anisotropy, current density, $j$, and moving velocity, $v_{m}$. " $\bigcirc$ ", " $\square$ ", " $"$ ", “ $\times$ ", and "+" indicate "completely developed", "under development", "not developed", "magnetically deteriorate", and "mechanically broken during annealing", respectively.

veloped by stress-annealing in nanocrystallized $\mathrm{Fe}$-based ribbon were reported by Ohnuma et al. [16], [17].

\section{B. Measurements}

We traced dc-hysteresis loops of the annealed ribbons and the prepared cores with a computer-aided B-H loop tracer (Riken BHS-40), and determined the saturation magnetization, $I_{s}$, the uniaxial anisotropy energy constant, $K_{u}$, and the anisotropy field, $H_{A}$, from the measured loop. $K_{u}$ was obtained by numerical integration of $H \cdot \Delta I$ in the first quadrant of the loop.

The annealed 500-mm-long ribbons were formed into toroidal cores using ceramic bobbins, and then their ac magnetic loss and relative permeability at $B_{m}=0.1 \mathrm{~T}$ were evaluated with a B-H analyzer (Iwatsu SY-8232) in the frequency, $f$, ranging from 0.1 to $2 \mathrm{MHz}$.

\section{RESULTS AND DISCUSSIONS}

\section{A. Optimization of Annealing Conditions}

In order to determine suitable annealing conditions for CSA-JH method, amorphous ribbons were annealed under various conditions, and then relationship among the development states of anisotropy, $j$ and $v_{m}$ was evaluated. Fig. 2 shows the results for the development state of anisotropy. The states were categorized into 5 ones based on the shape of hysteresis loops for the annealed ribbons. Symbols, " $\bigcirc$ ", " $\square$ ", "l", " $\times$ ", and "+", indicate "completely developed", "under development", "not developed", "magnetically deteriorated", and "mechanically broken during annealing", respectively. The completely developed anisotropy could be obtained stably at $v_{m}=1-200 \mathrm{~cm} / \mathrm{min}$ and $j=37.5 \mathrm{~A} / \mathrm{mm}^{2}$. The highest moving velocity of $200 \mathrm{~cm} / \mathrm{min}$ in our equipment corresponds to effective annealing time of approximately $1 \mathrm{sec}$, and enables us to reduce effective annealing time by $75 \%$ compared with that for the CSA-F method [7]. However, a ribbon annealed at high $v_{m}$ tended to wrinkle mechanically. From the viewpoint of forming the annealed ribbon into a toroidal core, the wrinkles should be improved in the future. In this experiment, we could obtain the ribbons with completely developed anisotropy and good mechanical stability below $v_{m}=10 \mathrm{~cm} / \mathrm{min}$.

Fig. 3 shows the dependence of anisotropy energy, $K_{u}$, on $\sigma$, together with results for the CSA-F [7] and JH [11] methods.

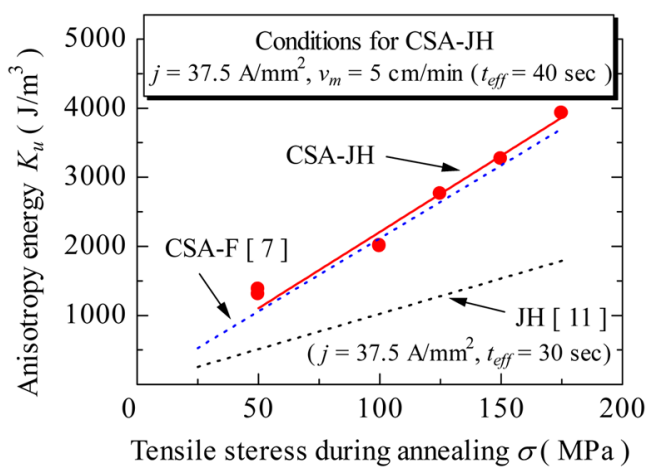

Fig. 3. Anisotropy energy of ribbons prepared by CSA-JH as a function of tensile stress during annealing. The results obtained by CSA-F and JH methods were also shown in the figure [7], [11] (Color version available online at http://ieeexplore.ieee.org.).

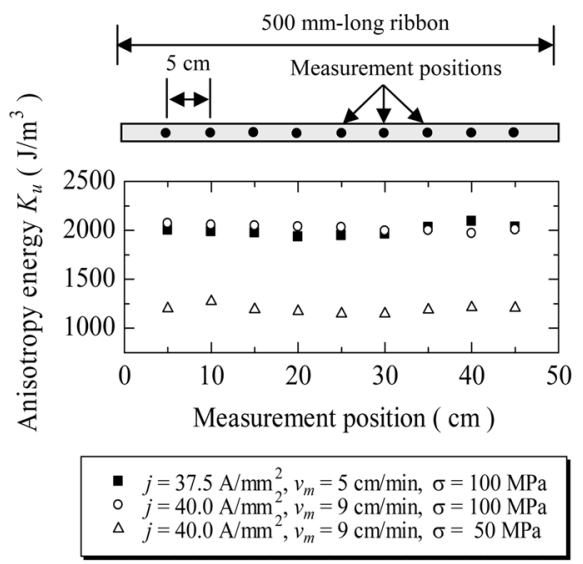

Fig. 4. Distribution of anisotropy energy, $K_{u}$, in a 500-mm-long ribbon prepared by CSA-JH method.

The slope of the $K_{u}$ vs $\sigma$ curve for the ribbons prepared by CSA-JH method was 2 times as large as that for JH method, indicating that a required $\sigma$ value can be reduced.

From the above results, we concluded that the CSA-JH method has high productivity compared with those for the CSA-F and JH methods.

\section{B. Distribution of Anisotropy in Annealed Ribbons}

In order to apply the long ribbon with controlled permeability to a toroidal core, $K_{u}$ of 500-mm-long ribbons was evaluated every $50 \mathrm{~mm}$ in length. The measurement was carried out using single-sheet tester (SST). The long ribbon inserted into pick-up coil, and then excited at $f=50 \mathrm{mHz}$. Lengths of an exciting coil and pick up one are 50 and $3 \mathrm{~cm}$, respectively. The exciting coil is long enough to guarantee a uniform magnetic field in the pick up coil. An error of the measurement is less than 5\%. Fig. 4 shows the measured $K_{u}$ at each measurement point. The $K_{u}$ value was almost constant in each point, and we could confirm that the CSA-JH method enables us to fabricate long ribbons with homogeneous anisotropy.

\section{AC Magnetic Properties of Prepared Core}

A toroidal core with the inner diameter, $D$, of $20 \mathrm{~mm}$ was prepared from a 500-mm-long annealed ribbon $\left(j=40 \mathrm{~A} / \mathrm{mm}^{2}\right.$, 


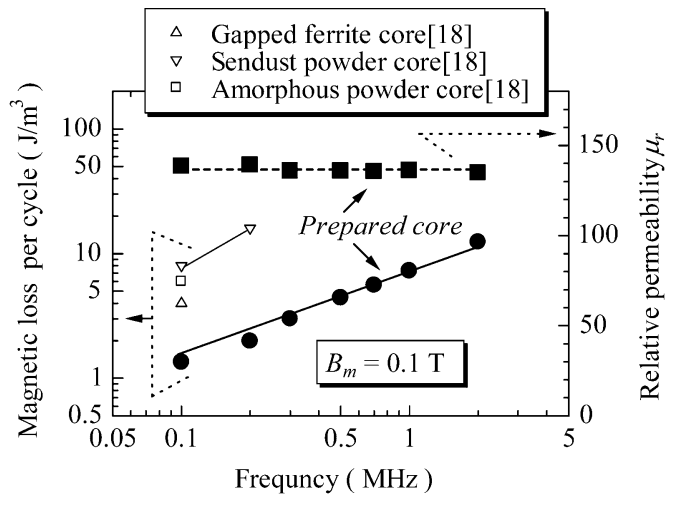

Fig. 5. Relative permeability, $\mu_{r}$, and magnetic loss of a developed core as a function of frequency, together with those for different types of cores with controlled permeability [18].

$v_{m}=9 \mathrm{~cm} / \mathrm{min}$ and $\sigma=100 \mathrm{MPa}$ ), and its ac magnetic properties were evaluated at $B_{m}=0.1 \mathrm{~T}$ in the frequency range from 0.1 to $2 \mathrm{MHz}$.

Fig. 5 shows relative permeability, $\mu_{r}$, and magnetic loss per cycle of the prepared core as a function of frequency, together with those for conventional cores with controlled permeability [18]. The prepared core had the low value of magnetic loss compared with those for the conventional ones, and also kept the permeability constant up to $2 \mathrm{MHz}$. These properties were almost the same as those for the previously reported ones [1]-[4].

\section{CONCLUSION}

We developed a fabrication method of continuous stress-annealing by Joule-heating (CSA-JH) which combined some productive advantages of the continuous stress-annealing with a furnace (CSA-F) and the Joule-heating (JH) methods for obtaining a magnetic ribbon with controlled permeability. The obtained results are summarized as follows;

1) The CSA-JH method achieved a significant reduction in an effective annealing time compared with that of the CSA-F method.

2) In the CSA-JH method, the magnitude of tensile stress during annealing for obtaining a suitable anisotropy energy value could be reduced compared with the $\mathrm{JH}$ method.

3) A toroidal core prepared from the ribbon obtained by the CSA-JH method had constant permeability up to $2 \mathrm{MHz}$ and showed lower magnetic loss than those for different types of cores with controlled permeability.

\section{REFERENCES}

[1] H. Fukunaga, N. Furukawa, H. Tanaka, and M. Nakano, "Nanostructured soft magnetic material with low loss and low permeability," J. Appl. Phys., vol. 87, pp. 7103-7105, May 2000.
[2] H. Fukunaga, H. Tanaka, T. Yanai, M. Nakano, K. Takahashi, Y. Yoshizawa, K. Isiyama, and K. Arai, "High performance nanostructured cores for choke coils prepared by using creep induced anisotropy," $J$. Magn. Magn. Mater, vol. 242-245, pp. 279-281, 2002.

[3] H. Fukunaga, T. Yanai, H. Tanaka, M. Nakano, K. Takahashi, Y. Yoshizawa, K. Ishiyama, and K. I. Arai, "Nanostructure metallic cores with extremely low loss and controlled permeability," IEEE Trans. Magn., vol. 38, pp. 3138-3140, Sep. 2002.

[4] T. Yanai, T. Ohya, K. Takahashi, M. Nakano, Y. Yoshizawa, and H. Fukunaga, "High temperature magnetic properties of $\mathrm{Fe}-\mathrm{Cu}-\mathrm{Nb}-\mathrm{Si}-\mathrm{B}$ cores with creep-induced anisotropy," IEEE Trans. Magn., vol. 40, pp. 2721-2723, Jul. 2004.

[5] F. Alves, J. B. Desmoulins, D. Hérisson, J. F. Rialland, and F. Costa, "Stress-induced anisotropy in Finemet- and Nanoperm-type nanocrystalline alloys using flash annealing," J.Magn. Magn. Mater, vol. 215-216, pp. 387-390, Jun, 2000.

[6] G. Herzer and N.-C. Liu, US Patent No. 6645 314, 2003.

[7] T. Yanai, T. Ohya, K. Takahashi, M. Nakano, and H. Fukunaga, "A new fabrication process of Fe-based ribbon with creep-induced anisotropy," J. Magn. Magn. Mater, vol. 290-291, pp. 1502-1505, 2005.

[8] N. Murillo, J. González, J. M. Blanco, J. M. González, and T. Kulik, "Stress annealing in $\mathrm{Fe}_{73.5} \mathrm{Cu}_{1} \mathrm{Nb}_{3} \mathrm{Si}_{13.5} \mathrm{~B}_{9}$ amorphous alloy: Induced magnetic anisotropy and variation of the magnetostriction constant," $J$. Appl. Phys., vol. 76, pp. 1131-1133, 1994.

[9] C. Miguel, A. P. Zhukov, and J. Gonzale, "Stress and/or field induced magnetic anisotropy in the amorphous $\mathrm{Fe}_{73.5} \mathrm{Cu}_{1} \mathrm{Nb}_{3} \mathrm{Si}_{15.5} \mathrm{~B}_{7}$ alloy: Influence on the coercivity, saturation magneto triction and magnetoimpedance response,” J. Phys. Stat. Sol., vol. 194, pp. 291-294, 2002.

[10] F. Alves and R. Barrué, "Anisotropy and domain patterns of flash stressannealed soft amorphous and nanocrystalline alloys," J. Magn. Magn. Mater, vol. 254-255, pp. 155-158, 2003.

[11] T. Yanai, M. Yamasaki, K. Takahashi, M. Nakano, H. Fukunaga, and Y. Yoshizawa, "Investigation of development process of creep-induced anisotropy in nanocrystalline $\mathrm{Fe}_{73.5} \mathrm{Cu}_{1} \mathrm{Nb}_{3} \mathrm{Si}_{15.5} \mathrm{~B}_{7}$ ribbon for mass production," in Proc. SMM 16 Conf., vol. 2, 2004, pp. 737-741.

[12] L. Kraus, K. Závěta, O. Heczko, P. Duhaj, G. Valsák, and J. Schneider, "Magnetic Anisotropy in as-quenched and stress-annealed amorphous and nanocrystalline $\mathrm{Fe}_{73.5} \mathrm{Cu}_{1} \mathrm{Nb}_{3} \mathrm{Si}_{13.5} \mathrm{~B}_{9}$ alloys," J. Magn. Magn. Mater, vol. 112, pp. 275-277, 1992.

[13] G. Herzer, "Creep-induced magnetic anisotropy in nanocrystalline Fe-Cu-Nb-Si-B alloys," IEEE Trans. Magn., vol. 30, pp. 4800-4802, Nov. 1994.

[14] N. Murillo, J. González, J. M. Blanco, J. M. González, and T. Kulik, "Stress annealing in $\mathrm{Fe}_{73.5} \mathrm{Cu}_{1} \mathrm{Ta}_{3} \mathrm{Si}_{13.5} \mathrm{~B}_{9}$ amorphous alloy: Induced magnetic anisotropy and variation of the magnetostriction constant," $J$. Appl. Phys., vol. 76, pp. 1131-1134, Jul. 1994.

[15] B. Hofmann and H. Kronmüller, "Creep induced magnetic anisotropy in nanocrystalline $\mathrm{Fe}_{73.5} \mathrm{Cu}_{1} \mathrm{Nb}_{3} \mathrm{Si}_{13.5} \mathrm{~B}_{9}$," Nanostructure Mater, vol. 6 , pp. 961-964, 1995.

[16] M. Ohnuma, K. Hono, T. Yanai, H. Fukunaga, and Y. Yoshizawa, "Direct evidence for structural origin of stress-induced magnetic anisotropy Fe-Si-B-Nb-Cu nanocrystalline alloys," Appl. Phys. Lett., vol. 83, pp. 2859-2861, 2003.

[17] M. Ohnuma, K. Hono, T. Yanai, M. Nakano, H. Fukunaga, and Y Yoshizawa, "Origin of the magnetic anisotropy induced by stress annealing in Fe-based nanocrystalline alloys," Appl. Phys. Lett., vol. 86, pp. 1-3, 2005.

[18] I. Endo, H. Tatumi, I. Otsuka, H. Yamamoto, A. Shintani, H. Koshimoto, M. Yagi, and K. Murata, "Magnetic properties of compressed amorphous powder core and their application to a fly-back converter," IEEE Trans. Magn., vol. 36, pp. 3421-3423, Sep. 2000.

Manuscript received March 13, 2006 (e-mail: t-yanai@net.nagasaki-u.ac.jp). 